This item was submitted to Loughborough's Research Repository by the author.

Items in Figshare are protected by copyright, with all rights reserved, unless otherwise indicated.

\title{
Counterpoint to "Infrared cameras overestimate skin temperature during rewarming from cold exposure"
}

PLEASE CITE THE PUBLISHED VERSION

https://doi.org/10.1016/j.jtherbio.2020.102663

PUBLISHER

Elsevier BV

VERSION

AM (Accepted Manuscript)

\section{PUBLISHER STATEMENT}

This paper was accepted for publication in the journal Journal of Thermal Biology and the definitive published version is available at https://doi.org/10.1016/j.jtherbio.2020.102663.

\section{LICENCE}

CC BY-NC-ND 4.0

\section{REPOSITORY RECORD}

Havenith, George, and Alex Lloyd. 2020. "Counterpoint to "infrared Cameras Overestimate Skin Temperature During Rewarming from Cold Exposure"'”. Loughborough University. https://hdl.handle.net/2134/12656123.v1. 


\section{SHORT COMMUNICATION}

Counterpoint to "Infrared cameras overestimate skin temperature during rewarming from cold exposure"

\section{George Havenith* and Alex B Lloyd}

Environmental Ergonomics Research Centre, School of Design and Creative Arts, Loughborough University, LE11 3TU, UK.

${ }^{*}$ Correspondence:

Professor George Havenith

Environmental Ergonomics Research Centre

Loughborough University

Loughborough, LE11 3TU

Leicestershire, UK

E: G.Havenith@lboro.ac.uk

Phone 01509223031

Highlights

We evaluated Maley et al.(2020) for accuracy and support for its title and conclusion

Several issues with the methodology and interpretation were identified.

Their conclusion is insufficiently supported by evidence presented in the paper.

keywords

Infrared thermography; skin temperature measurement; instrument validity; measurement error 


\begin{abstract}
We evaluated the paper by Maley et al. (2020) in this journal "Infrared cameras overestimate skin temperature during rewarming from cold Exposure" for the evidence provided in support of its title and conclusions. Several methodological issues were identified as well as issues with the data interpretation: 1: Only one camera was used but a conclusion was made for 'cameras' in general; 2 : The camera accuracy $\left( \pm 2^{\circ} \mathrm{C}\right)$ is too low to do a meaningful comparison without using local reference values or an on-site calibrator with higher accuracy; 3: Thermistor measurements are taken as gold standard while issues such as temperature gradients and taping are known; 4: Both methods are not compared at the same location and a natural, physiological, gradient may be present between their locations; 5 . The impact of the sensor and tape on delays in the change of the underlying tissue temperature is not considered; 6 : Only a single pixel was used for the analysis, which has been shown to be problematic.

We concluded that the paper by Maley et al. does not provide conclusive evidence that infrared cameras overestimate skin temperature during rewarming from cold exposure.
\end{abstract}

\title{
SHORT COMMUNICATION - Counterpoint to "Infrared cameras overestimate skin temperature during rewarming from cold exposure"
}

With great interest we have read the paper by Maley et al. (2020) in the Journal of Thermal Biology, in which the authors measure the rewarming of a hand after water immersion cooling to around $15^{\circ} \mathrm{C}$ skin temperature $\left(8^{\circ} \mathrm{C}\right.$ water temperature, $30^{\circ} \mathrm{C}$ environmental temperature). In this study, the authors compare finger pad skin temperature measurements with a taped thermistor (Type EUS-U, Grant Instruments, UK) to measurements with an infrared camera (A320G, FLIR Systems, UK) at a 1-cm distal skin area. As the title suggests, they conclude that infrared cameras should not be used in such applications, as they deviate too much from an equivalent thermistor measurement. Based on our interpretation of the data and methodology however, we have some concerns regarding the title and the conclusions of the paper.

Our first concern is the use of the plural term "cameras" in the present study (e.g. title), which suggests that the present observations are representative of all Infra-red cameras. The authors have however only collected data with a single camera. It is therefore conceivable that other cameras, even of the same type, could give quite different results, especially given this camera model (A320G, FLIR Systems, UK), after factory calibration, is listed to have an accuracy of the higher of $\pm 2 .{ }^{\circ} \mathrm{C}$ or $2 \%$ of the reading, i.e. $2^{\circ} \mathrm{C}$ in the used range (Flir, 2016).

Our second concern is related to the calibration details, in which the authors state 'the infrared camera was calibrated in the last 12 months'. We assume they refer to a factory calibration, rather than an additional local calibration during the experiment. A local calibration with a specialised infrared calibrator or temperature reference plates is the recommended procedure in the use of infrared cameras for medical application and/or skin temperature measurement (Ring \& Ammer, 2010, 2012, Simpson et al. 2008, Fournet et al. 2013). Given the absence of a local calibration, this implies that the observed mean bias of $1.8^{\circ} \mathrm{C}$ is within the stated accuracy for this camera model. Cameras of the same model could, within the stated accuracy, be reading up to $4^{\circ} \mathrm{C}$ lower, and thus produce the opposite conclusion. Other 
infrared cameras have a substantially higher accuracy, though still typically $\pm 1^{\circ} \mathrm{C}$ after factory calibration.

Apart of providing a stability check of the camera and a check of the factory calibration, assuming an accurate reference temperature is used (with higher accuracy than the camera), the addition of an infrared calibrator or reference plates in the images could increase the accuracy of the measurement substantially (Ring \& Ammer, 2010, 2012, Simpson et al. 2008, Fournet et al. 2013). Further improvements could be achieved by averaging the temperature over an area of the finger, potentially looking for the mean or maximum with that area (Ludwig et al. 2014) rather than relying on a single camera pixel in the 'spot tool', which changes the camera factually into an infrared spot meter. Maniar et al. (2015) advise against the use of single pixels in comparing data to contact sensors, while Priego Quesada et al. (2015) have shown that temperatures measurements including more pixels tend to differ from those with a small number of pixels.

In their analysis, it seems that the authors assume a priori that their thermistor provides the correct/true value for the rewarming skin temperature, rather than the infrared measurement. Several studies have compared contact and infrared measurements, but in their evaluation consider potential issues with both techniques (de Andrade Fernandes et al. 2014; Priego Quesada et al. 2015; Buono \& Ulrich, 1998). Looking specifically at issues with contact measurements, various papers have documented substantial variations in temperature measured with different thermal contact sensors and have furthermore shown substantial impact of both the method of fastening the sensor, and of the surface-microclimate gradient. MacRae et al. (2018) varied the air temperature while the sensor (same thermistor type used as in the current study, fixed with similar tape), was taped against an aluminium temperaturecontrolled plate, for which temperature was varied stepwise as well. They observed that for a $35^{\circ} \mathrm{C}$ environment, the surface temperature range for which the sensor bias was below $0.5^{\circ} \mathrm{C}$ was limited to 32.6 to $38.5{ }^{\circ} \mathrm{C}$ surface temperature. Likewise, at $25^{\circ} \mathrm{C}$ environmental temperature, sensor bias within $0.5^{\circ} \mathrm{C}$ was limited to $22.2-28.2^{\circ} \mathrm{C}$ surface temperature. This indicates that thermistors, used with similar tape as in the Maley et al. study, are only accurate within $0.5^{\circ} \mathrm{C}$, within a range of approximately $\pm 3^{\circ} \mathrm{C}$ surface to environmental temperature gradients. Thus, for the present study, where air temperature was $30^{\circ} \mathrm{C}$, the range of surface temperatures that would achieve a bias below $0.5^{\circ} \mathrm{C}$ would be approximately 27 to $33^{\circ} \mathrm{C}$ skin temperature. At an air temperature $13^{\circ} \mathrm{C}$ below surface temperature, MacRae et al. (2018) observed substantial deviations (underestimation) for the Grant thermistor (with e.g. Tegaderm tape) of around $1.9^{\circ} \mathrm{C}$. In the present experiment such an under-estimation would be expected during the cooling process in the colder water, which would reverse into a potential over-estimation during the warmup as air temperature in the present experiment was up to $15^{\circ} \mathrm{C}$ higher than skin temperature. Furthermore, Psikuta et al. (2014) showed a high sensitivity of the thermistor measured value to the type of tape used, also interacting with the temperature gradient between surface and surrounding air. For the Grant thermistor, at a gradient of $16.5^{\circ} \mathrm{C}$, the bias for a similar tape (Tegaderm) was around $2.5^{\circ} \mathrm{C}$, while at a gradient of less than $2^{\circ} \mathrm{C}$ it was below $0.5^{\circ} \mathrm{C}$. While in Psikuta et al. (2014) the air was cooler than the surface, and in the Maley et al. (2020) experiment it was warmer than the surface, the gradients studied were similar, and thus impacts of similar magnitude, but in the opposite direction, could be expected in Maley et al.'s study. The studies by MacRae et al. (2018) and Psikuta et al. (2014) show in our opinion that taking the thermistor values as true reference value is questionable.

A further potential issue is the interaction of a physiological system, the hand, with the sensor. While the authors discuss the sensor's fast response rate, they do not consider warming patterns of the hand, and that covering the skin with a sensor can impact the skin temperature itself. If the rewarming is purely via blood flow into the hand, hands tend to warm distal to 
proximal (Daanen 1997), potentially causing a systematically higher temperature for the distal camera measurement. Further, if a good part of the rewarming comes from convective warming by the relatively warm environment, the insulation by the sensor and tape and the related delay in skin warming may cause this area to trail behind in warming when compared to uncovered skin. While in the experiment it was not possible to measure both techniques at the same spot (the ideal situation), it would have been better to measure the infrared pixel (ideally an area) between two thermistors rather than distal to just one.

Finally, we would have expected a comparison of the two measurement techniques at a fixed and steady substrate temperature, ideally without the physiological variability introduced across the hand and without a potential interaction of the sensor with the hand, to determine the presence of bias in the absence of heating or cooling. The paper does not mention such a check.

Given the various concerns raised, we conclude that the paper by Maley et al. (2020) does not provide conclusive evidence that infrared cameras overestimate skin temperature during rewarming from cold exposure.

\section{References}

1. Buono, M.J., Ulrich, R.L., 1998. Comparison of mean skin temperature using "covered" versus "uncovered" contact thermistors. Physiol. Meas. 19 (2) (1998) 297-300.

2. Daanen, H.A.M., 1997. Central and peripheral control of finger blood flow in the cold. Thesis, Free University Amsterdam.

3. de Andrade Fernandes, A., dos Santos Amorim, P.R., Brito, C.J., de Moura, A.G., Moreira, D.G., Costa, C.M.A., Sillero-Quintana, M. and Marins, J.C.B., 2014. Measuring skin temperature before, during and after exercise: a comparison of thermocouples and infrared thermography. Physiological measurement, 35(2), p.189.

4. FLIR. 2020. model A320 camera manual (downloaded 04/05/2020; page 105.) https://mds-

flir.com/post_file_download.cm?c=YTo0OntzOjEwOiJib2FyZF9jb2RIljtzOjlyOiJiMjAxODA 2MDg1YjE5YmQ3YTMxMzEzljtzOjk6InBvc3RfY29kZSI7czoyMjoicDIwMTgwNjA4NWIxO WMwNGQ4OGRmMSI7czo5OiJmaWxIX2NvZGUiO3M6MjI6InAyMDE4MDYwODViMTlj MDRkYjAzNDgiO3M6MTE6Im1lbWJIcl9jb2RIljtOO30=

5. Fournet, D., Ross, L., Voelcker, T., Redortier, B. and Havenith, G., 2013. Body mapping of thermoregulatory and perceptual responses of males and females running in the cold. Journal of Thermal Biology, 38(6), pp.339-344.

6. Ludwig, N., Formenti, D., Gargano, M., \& Alberti, G. 2014. Skin temperature evaluation by infrared thermography: Comparison of image analysis methods. Infrared Physics \& Technology, 62(0), 1-6. doi: http://dx.doi.org/10.1016/j.infrared.2013.09.011

7. MacRae, B.A., Annaheim, S., Stämpfli, R., Spengler, C.M. and Rossi, R.M., 2018. Validity of contact skin temperature sensors under different environmental conditions with and without fabric coverage: Characterisation and correction. International journal of biometeorology, 62(10), pp.1861-1872. https://doi.org/10.1007/s00484-018-1589-0

8. Maley, M.J., Hunt, A.P., Bach, A.J., Eglin, C.M. and Costello, J.T., 2020. Infrared cameras overestimate skin temperature during rewarming from cold exposure. Journal of Thermal Biology, p.102614. https://doi.org/10.1016/j.jtherbio.2020.102614

9. Maniar, N., Bach, A.J., Stewart, I.B. and Costello, J.T., 2015. The effect of using different regions of interest on local and mean skin temperature. Journal of thermal biology, 49 , pp.33-38. 
10. Psikuta, A., Niedermann, R. and Rossi, R.M., 2014. Effect of ambient temperature and attachment method on surface temperature measurements. International journal of biometeorology, 58(5), pp.877-885.

11. Quesada, J.I.P., Guillamón, N.M., de Anda, R.M.C.O., Psikuta, A., Annaheim, S., Rossi, R.M., Salvador, J.M.C., Pérez-Soriano, P. and Palmer, R.S., 2015. Effect of perspiration on skin temperature measurements by infrared thermography and contact thermometry during aerobic cycling. Infrared Physics \& Technology, 72, pp.68-76.. https://doi.org/10.1016/j.infrared.2015.07.008.

12. Ring, E. F. J., \& Ammer, K. 2000. The Technique of Infra red Imaging in Medicine. Thermology International, 10(1), 7-14.

13. Ring E.F., Ammer K. Infrared thermal imaging in medicine. Physiological measurement. 2012 Feb 28;33(3):R33.

14. Simpson, R.C., McEvoy, H.C., MacHin, G., Howell, K., Naeem, M., Plassmann, P., Ring, F., Campbell, P., Song, C., Tavener, J. and Ridley, I., 2008. In-field-of-view thermal image calibration system for medical thermography applications. International Journal of Thermophysics, 29(3), pp.1123-1130. 